\title{
HACIA LA DESJUDICIALIZACIÓN DE LA EJECUCIÓN CIVIL
}

\author{
TOWARDS DEJUDICIALIZATION OF CIVIL ENFORCEMENT
}

\section{Macarena Vargas Pavez}

\begin{abstract}
RESUMEN: La creciente tendencia hacia la desjudicialización de la ejecución ha generado una amplia discusión en la doctrina nacional. Uno de los debates más interesantes es aquel que pretende determinar si este proceso de racionalización de la intervención judicial es respetuoso de las normas constitucionales que regulan la función jurisdiccional. Examinar los argumentos a favor y en contra de esta postura y aquellos que justifican la desjudicialización de la ejecución en sistema nacional es el objetivo de este trabajo.
\end{abstract}

Palabras clave: Ejecución, desjudicialización, proceso civil.

ABSTRACT: The increasing trend towards the dejudicialization of the judgement enforcement has generated a wide discussion among national legal scholars. One of the most interesting debates consists in trying to determine if this judicial intervention`s rationalization process is respectful of the jurisdictional function`s constitutional framework. Tje aim of this paper es to examine the arguments in favor and against this position, and those that justify enforcement dejudicialization in the national system.

Key words: Enforcement, dejudicialization, civil procedure.

\section{INTRODUCCIÓN}

Tal vez una de las modificaciones más innovadoras de la Reforma a la Justicia Civil sea la desjudicialización de la ejecución. Esto es, la sustracción de la órbita judicial de algunas fases del procedimiento ejecutivo, las que son entregadas a un órgano o agente distinto del juez.

En el proyecto de ley del Código Procesal Civil -presentado por el Ejecutivo en marzo del 2012 al Congreso Nacional- esta innovación se materializa a través de la creación de la figura del oficial de ejecución. Ella se inserta dentro de una creciente tendencia mundial de racionalización de la intervención judicial en materia ejecutiva.

La propuesta del Ejecutivo ha generado una amplia discusión en la doctrina nacional. Se cuestiona, por una parte, si este proceso de desjudicialización es necesario y viable y, por otra, si es respetuoso de las normas constitucionales que regulan la función jurisdiccional.

Algunos sostienen que atendido lo dispuesto en el artículo 76 de la Constitución Política del Estado la ejecución es una facultad inescindible de la función jurisdiccional, de

\footnotetext{
* Abogada, Universidad Diego Portales, Magíster en Gestión y Políticas Públicas, Universidad de Chile, Profesora de Derecho Procesal, Universidad Diego Portales, alumna del programa de Doctorado en Derecho, Pontificia Universidad Católica de Valparaíso, dirección: República 105, Santiago, e-mail: macarena.vargas@udp.cl. Teléfono: 676-2609. El presente trabajo corresponde a una investigación realizada en el marco del programa de Doctorado y fue dirigida por el Prof. Dr. Álvaro Pérez Ragone.
} 
modo tal que ejecutar o hacer ejecutar lo juzgado es una tarea que compete solo a los tribunales de justicia establecidos en la ley. Señalan que una modificación como la propuesta infringiría la carta fundamental, requiriéndose en ese evento de una reforma constitucional.

Otros, en cambio, advierten que es posible sustraer del ámbito judicial algunas fases del procedimiento ejecutivo, en particular aquellas que carecen de contencioso, pues no ameritarían la intervención de un juez. Además de consideraciones de política pública, quienes apoyan esta postura plantean que las deficiencias que exhibe hoy nuestro sistema de ejecución atentan contra la garantía constitucional de acceso a la justicia del acreedor, quien tiene derecho a recuperar su crédito en forma eficiente y dentro de un tiempo razonable.

En este contexto, el trabajo que a continuación se presenta tiene un doble propósito. Por una parte, tiene por objeto presentar argumentos que permiten apoyar la propuesta de desjudicialización de la ejecución civil contenida en el proyecto de ley y, por otra, hacerse cargo de aquellas voces que sostienen que una modificación de este tipo pugna con la Carta Fundamental y exige por tanto una reforma constitucional.

Para ello, en la primera sección se revisan los argumentos para afirmar la necesidad y viabilidad de la desjudicialización de la ejecución en tanto facultad conexa a la jurisdicción y como un remedio para que el acreedor pueda alcanzar la conformidad de su crédito en forma oportuna. En la segunda parte se presentan las razones por las cuales se considera que la propuesta del Ejecutivo no infringe el artículo 76 de la carta fundamental y, por ende, una modificación de estas características no amerita una reforma del texto constitucional.

\section{HACIA LA DESJUDICIALIZACIÓN DE LA EJECUCIÓN CIVIL}

\subsection{Tendencias actuales en el derecho comparado.}

De un tiempo a esta parte se ha venido discutiendo acerca de la viabilidad de entregar a órganos distintos del juez algunas o todas las fases que componen el procedimiento ejecutivo, esto es, desjudicializar la ejecución en sede civil. En gran parte de Europa, la legislación procesal contempla distintos mecanismos de racionalización de la intervención judicial, principalmente en aquellas cuestiones estrictamente no jurisdiccionales, como sucede por ejemplo en la etapa de realización de los bienes.

Ello se debe, en primer término, a los aportes efectuados por la doctrina contemporánea ${ }^{1}$ y, en segundo lugar, al consenso que existe sobre la necesidad de dotar de mayor eficacia la ejecución de los créditos por las múltiples deficiencias que el procedimiento ejecutivo presenta para la concreción de las decisiones judiciales dentro de un plazo razonable.

El derecho procesal civil europeo de los últimos años muestra diversos formatos de desjudicialización de la ejecución civil. Muchos países han modificado su legislación y han adoptado distintos modelos que difieren según sean más o menos centralizados, según la regulación y calificación que se exige a los encargados de la ejecución y según el tipo de órganos y agentes que desempeñaran esta tarea ${ }^{2}$.

\footnotetext{
1 Marinoni (2010) p. 115.

2 Hess (2005) pp. 25-51.
} 
En relación a este último punto, se pueden distinguir cuatro modelos que van desde sistemas de ejecución a cargo de funcionarios judiciales, como ocurre en España, pasando por agencias administrativas independientes del Poder Judicial, como en el caso de Suiza, hasta la entrega de la tarea de ejecutar a oficiales estatales supervisados por la autoridad (oficiales de ejecución), como sucede, por ejemplo, en Holanda ${ }^{3,4}$.

El interés por efectivizar la ejecución no solo se verifica en forma particular en la legislación de algunos países europeos sino que constituye una preocupación de carácter global de la Unión Europea. Se busca armonizar los sistemas legales, pues las diferencias entre las legislaciones nacionales aumentan los costos y hacen impracticable la ejecución del crédito. Se ha sostenido que -en el marco de la Unión Europea- el desarrollo de la ejecución de los créditos no ha ido a la par con el desarrollo de los mercados internacionales, cuestión que se ha intentado revertir de variadas formas.

La experiencia europea muestra que en la gran mayoría de las legislaciones la ejecución está a cargo de oficiales estatales (huissiers de justice o bailiffs) supervisados por la autoridad, pero operan fuera del sistema judicial y sin intervención de jueces y/o funcionarios judiciales, tal como ocurre en Bélgica, Escocia y Portugal, por mencionar algunos países 5 . En general, se trata de profesionales especializados, quienes pueden ejercer libremente la profesión, como sucede por ejemplo en Hungría o Irlanda o bien pueden desempeñarse en una institución pública, como ocurre por ejemplo en Austria, Dinamarca o Italia ${ }^{6}$.

Las funciones de estos agentes varían de una legislación a otra, pero en general se trata de profesionales autorizados por el Estado para hacer cumplir los títulos ejecutivos, para efectuar actos de comunicación referidos a la ejecución, realizar los bienes del ejecutado, por ejemplo a través de subastas públicas. En algunos casos, dependiendo de la legislación vigente, pueden además cumplir otro tipo de funciones como la administración de bienes inmuebles, la redacción de contratos y, en general, la prestación de servicios de asesoría legal ${ }^{7}$.

Por ejemplo, en Francia los huissiers de justice tienen el monopolio de la ejecución y sus honorarios son pagados por el deudor, de acuerdo a un arancel público ${ }^{8}$. Son nombrados por el Ministerio de Justicia, luego de un estricto proceso de selección. Se exige a los postulantes contar con el título de abogado, participar en un programa de entrenamiento de dos años en la oficina de un oficial de ejecución, cursar estudios de especialización y rendir un examen. Estos profesionales se encuentran agrupados en la Chambre Nacionale des Huissiers de Justicie $(\mathrm{CNHJ})^{9}$ y prestan sus servicios en un territorio jurisdiccional determinado en función del domicilio del deudor ${ }^{10}$. Aun cuando se trata de agentes que operan fuera del sistema judicial su función puede verse potencialmente ligada a la actividad juris-

\footnotetext{
3 Villadiego (2008).

4 Andenas (2005) pp. 7-23. Pérez Ragone y Miquel Sala (2010) pp. 1-16.

5 Villadiego (2008) p. 30.

6 Villadiego (2008) p. 34.

7 http://www.uihj.com (24 de octubre de 2012).

8 ThÉRY (1997) pp. 261-318.

9 Para mayor información véase: http://www.huissier-justice.fr/. Página visitada el 24 de octubre 2012.

10 http://www.uihj.com (24 de octubre de 2012).
} 
diccional. Ello ocurre cuando el ejecutado discute la procedencia de la ejecución, situación que es conocida y resuelta por los llamados juge de l'execution (jueces de ejecución) ${ }^{11}$.

Inglaterra, por su parte, ha experimentado una profunda reforma en materia de ejecución a través de leyes procesales y orgánicas. The Tribunals, Courts and Enforcement Act de 2007 es una de ellas e introduce varias modificaciones, entre las cuales destaca un nuevo régimen para "tomar el control" de los bienes del ejecutado, nuevos métodos para obtener información acerca de los activos y pasivos de este y además un paquete de medidas para ayudar a los demandados dispuestos a pagar sus deudas en el mediano y largo plazo ${ }^{12}$.

Desde una perspectiva orgánica, se trata de un sistema descentralizado, tanto a nivel de tribunales inferiores como superiores de justicia. En los county court los procedimientos ejecutivos están a cargo de los certificated bailiffs, mientras que en la High Court estas funciones se han entregado a los denominados High Court Enforcement Officers (HCEOs) ${ }^{13}$. Los certificated bailiffs pueden formar parte del staff del tribunal o bien pueden ser empleados de una empresa privada que ofrece sus servicios a la comunidad. Si bien esta figura fue creada en el 2000, su implementación ha sido postergada por la necesidad de dictar normas complementarias. Se estima que la puesta en marcha de estos oficiales se producirá el año 2012.

Los HCEOs fueron creados en el 2004 y se encuentran plenamente operativos. El nombramiento de estos oficiales corresponde a la High Court, luego de un exigente proceso de selección. Una vez elegidos, estos profesionales pueden ofrecer sus servicios a las personas que necesiten hacer ejecutar órdenes judiciales superiores a 600 libras (poco más 680 euros). Sus servicios incluyen no solo el cobro de las deudas, sino que también la redacción de informes de derecho, traslados de órdenes judiciales desde los tribunales inferiores a la High Court, investigación sobre los bienes del ejecutado, entre otras ${ }^{14}$.

En Iberoamérica también es posible observar manifestaciones orientadas hacia la desjudicialización de la ejecución civil. Varios países han introducido medidas para perfeccionar y corregir sus procedimientos ejecutivos debido a la ineficacia que ellos presentan y la consecuente vulneración al debido proceso y a la noción de plazo razonable que esto conlleva ${ }^{15}$.

El estudio realizado por De Hegedus y Romero señala que uno de los mecanismos de corrección utilizados en las legislaciones iberoamericanas -además de las astrientes- es la desjudicialización de algunas fases de la ejecución. Ello opera principalmente al momento de la subasta judicial, entregando a un agente u órgano la tarea de comercializar el bien, como ocurre con distintas modalidades y para distintos tipos de créditos, en España, Uruguay, Argentina y México ${ }^{16}$.

En España, por ejemplo, debido al mal funcionamiento del sistema que permitía la realización de los bienes a bajos precios y a través de maniobras fraudulentas, la Ley de Enjuiciamiento Civil 1/2000 incorporó dos nuevas modalidades para la realización forzo-

\footnotetext{
11 Hess (2005) pp. 25-51.

12 Andrews y Turner (2010) p. 128.

13 Hess (2010) p. 47.

14 Turner (2010) p. 142.

15 De Hegedus y Romero (2010) pp. 516-549.

16 De Hegedus y Romero (2010) pp. 535 a 549.
} 
sa de los bienes a través de entidad o persona especializada y/o por medio de un convenio privado de realización ${ }^{17}$. Se crea así la Oficina Judicial y se modifica la distribución de funciones entre el juez y el secretario judicial del tribunal, entregando a este último facultades de acordar los medios o instrumentos ejecutivos previstos en la ley para que la ejecución sea judicialmente despachada (artículo 545.4 LEC) ${ }^{18,19}$.

\subsection{LA EJECUCIÓN EN SISTEMA PROCESAL CIVIL CHILENO}

Una segunda razón por la cual considero que la desjudicialización de la ejecución debe ser apoyada se funda en la evidencia empírica.

En el caso chileno la ejecución civil no escapa del diagnóstico de los otros sistemas iberoamericanos. A las deficiencias antes mencionadas se suma la lentitud y ritualidad del procedimiento ejecutivo, el exceso de excepciones que puede oponer el ejecutado y la saturación de los tribunales civiles ${ }^{20}$. A ellas hay que añadir algunos elementos propios de la legislación y de la práctica forense que vale la pena analizar y que dicen relación con los incentivos al litigio que operan en nuestro ordenamiento jurídico.

Datos estadísticos provenientes de la Corporación Administrativa del Poder Judicial sobre las causas terminadas en el año 2009 indican que el 96\% de la carga actual de los tribunales civiles corresponde a procesos de cobranza de créditos $^{21}$. La cifra se desglosa del siguiente modo:

- Juicio ejecutivo de obligación de dar: 70,6\%.

- Gestión preparatoria de citación a confesar deuda: 24,0\%.

- Gestión preparatoria de notificación de protesto de cheque, letra y pagaré: 1,4\%.

Estas cifras muestran la alta concentración de causas ejecutivas en la composición del litigio civil, lo que ha llevado a algunos a sostener que los tribunales civiles se han transformado en "verdaderas oficinas de cobranzas del sistema bancario y financiero" 22.

A ello debemos añadir otro elemento que ayuda a vislumbrar con mejor claridad el complejo panorama de la ejecución en nuestro sistema, esto es, las formas en que estos procedimientos finalizan. El siguiente cuadro muestra los principales tipos de término de juicios ejecutivos finalizados durante el año $2009^{23}$.

Como se puede observar, los tres primeros tipos de término -que en conjunto acumulan más del 96\% de los casos- corresponden a procedimientos en los cuales la tramita-

17 Cerato (2009) p. 238.

18 Ortells (2010) p. 603.

19 Ley Orgánica 1/2009, de 3 de noviembre, complementaria de la Ley de reforma de la legislación procesal para la implantación de la nueva Oficina judicial, por la que se modifica la Ley Orgánica 6/1985, de 1 de julio, del Poder Judicial.

20 RiEd (2006) pp. 475-491.

21 Centro de Estudios de Justicia de las Américas (2011) p. 15. Cabe señalar que el procedimiento ordinario corresponden a 11.658 causas, lo que equivale al 1,46\% del total.

22 De la Fuente (2009) p. 470.

23 Centro de Estudios de Justicia de las Américas (2011) p. 26. 
ción real es muy baja, por no decir casi nula. Además, solo el 1,7\% de los casos finaliza con una respuesta efectiva a la pretensión del demandante, ya sea a través del pago del crédito $(1.3 \%)$ o la dictación de una sentencia definitiva $(0.4 \%)^{24}$.

\begin{tabular}{|c|c|c|}
\hline Tipo de término & Total & $\%$ \\
\hline Téngase por no presentada la demanda & 644.166 & 82.8 \\
\hline Demanda sin movimiento & 77.913 & 10.0 \\
\hline No da curso a la demanda & 26.543 & 3.4 \\
\hline Retiro de la demanda & 11.917 & 1.5 \\
\hline Pago del crédito & 9.906 & 1.3 \\
\hline Sentencia definitiva & 2.829 & 0.4 \\
\hline
\end{tabular}

La alta concentración de salidas tempranas del juicio ejecutivo - "téngase por no presentada la demanda", "demanda sin movimiento" o "no da curso a la demanda"- se puede explicar en parte por la normativa que el Servicio de Impuestos Internos impone para el castigo de créditos incobrables. Uno de los requisitos para admitir la deducción de castigos es "haber agotado prudencialmente los medios de cobro", lo que el acreedor puede hacer de diversas formas (llamadas telefónicas, cartas certificadas, entre otras) ${ }^{25}$. Si se trata de deudas superiores a 50 Unidades de Fomento (aproximadamente un millón de pesos) se exige además "haber requerido judicialmente al deudor y haber realizado las actuaciones procesales propias y razonables del procedimiento judicial de que se trate" 26 .

Ello significa que el acreedor para castigar sus deudas incobrables debe necesariamente iniciar un procedimiento ante los tribunales y requerir de pago al ejecutado, aun cuando tengan bajas expectativas de recuperar lo adeudado o incluso tenga la certeza de que no podrá hacerlo. Es decir, muchos demandantes ponen en movimiento todo el aparato jurisdiccional sin tener interés en obtener un pronunciamiento judicial, sino que lo hacen exclusivamente con la finalidad de cumplir con la normativa tributaria vigente.

Ahora bien, en los casos en que el proceso sigue adelante, es decir, en aquellos en que la demanda es notificada y se requiere de pago al deudor, se observa una muy baja proporción de oposición de excepciones por parte del ejecutado. Conforme a los datos proporcionados por la CAPJ en los años 2009 y 2010 los juicios ejecutivos con oposición de excepciones alcanzan solo a un $2 \%$ de los casos, lo que da cuenta de la casi nula presencia de fases contenciosas dentro del actual procedimiento ejecutivo chileno ${ }^{27}$.

Reflexiones de este tipo, además de aquellas relativas al impacto económico de estos juicios y a la inequidad que supone la inversión de recursos del Estado en un tipo de causas ligadas al crédito se tuvieron en consideración para proponer la desjudicialización de

\footnotetext{
24 Centro de Estudios de Justicia de las Américas (2011) p. 51.

25 Circular No 24 de 24 de abril del 2008 sobre "Tratamiento tributario del castigo de créditos incobrables". http://www.sii.cl/documentos/circulares/2008/circu24.htm. Página visitada el 24 de octubre de 2012.

26 Circular No 24 de 24 de abril del 2008.

27 Centro de Estudios de Justicia de las Américas (2011) pp. 35 y 36.
} 
algunas fases del procedimiento ejecutivo en el proyecto de ley que crea el Código Procesal Civil ${ }^{28,} 29$.

En este sentido, el proyecto de ley contempla la figura del oficial de ejecución ante quien se presentará una solicitud de ejecución y prevé también la intervención del juez en el evento de oposición de excepciones (demanda de oposición a la ejecución) por parte del ejecutado y otros trámites de naturaleza contenciosa ${ }^{30}$.

Como se puede observar, el Ejecutivo opta por un modelo intermedio, no completamente centralizado como el español, pero tampoco totalmente descentralizado como el suizo. Si bien se sustraen de la intervención judicial algunas de las etapas del proceso ejecutivo, como el embargo y la realización de los bienes, el órgano jurisdiccional mantiene su potestad para dirimir -además de las excepciones- todas las cuestiones controvertidas que surjan durante el proceso.

\section{ARGUMENTOS PARA SOSTENER QUE NO ES NECESARIA UNA REFORMA CONSTITUCIONAL}

Si bien en la doctrina nacional existe meridiano consenso en torno a la propuesta del Ejecutivo, se alzan algunas voces que discuten si la entrega de algunas fases del procedimiento ejecutivo a órganos distintos del juez -especialmente si se trata de agentes ajenos al Poder Judicial- es respetuosa de las normas constitucionales. Ello, pues la ejecución, conforme a lo dispuesto en la Carta Fundamental, sería una facultad inescindible de la función jurisdiccional que corresponde exclusivamente a los tribunales de justicia, por ende una modificación orientada hacia su desjudicialización ameritaría una reforma constitucional.

A continuación se presentan algunos de los argumentos que se pueden esgrimir para sostener que ello no es necesario.

\subsection{LA Historia CONSTITUCiONAL.}

Como se verá a continuación, parte de la doctrina procesal postula una visión comprensiva e integral de la tarea jurisdiccional que incluye la facultad de hacer ejecutar lo juzgado. Así, se considera que los procedimientos ejecutivos son una manifestación de la función jurisdiccional, tal como lo son los procedimientos declarativos.

"La actividad ejecutiva es actividad jurisdiccional” decía Couture en $1942^{31}$. El autor uruguayo sostiene que aun cuando en los procedimientos ejecutivos sea más visible la acción de los auxiliares de justicia que la de los jueces -lo que se debe a una dele-

28 De la Fuente (2009) p. 470.

29 Mensaje S.E. el Presidente de la República con el que se inicia un proyecto de ley que establece el Nuevo Código Procesal Civil. Santiago, 12 de marzo de 2012. Mensaje No 004-360/.

30 Artículos 422 y siguientes del proyecto de ley.

31 Couture (1987) p. 443. 
gación que hacen estos últimos a los primeros- ello no significa bajo ningún punto de vista que se pueda prescindir de la intervención judicial ${ }^{32}$.

En esta misma línea, Juan Montero Aroca considera que la jurisdicción no se limita a la declaración del derecho, sino que comprende la ejecución de sus resoluciones judiciales. La ejecución civil es parte integrante y esencial de la jurisdicción, porque la satisfacción de las pretensiones se logra con el cumplimiento o la ejecución forzosa de lo declarado en la sentencia. Adhiriendo a las teorías objetivas este autor define la jurisdicción como la "potestad dimanante de la soberanía del Estado ejercida exclusivamente por tribunales independientes y predeterminados por la ley, de realizar el derecho en el caso concreto juzgado de modo irrevocable y ejecutando lo juzgado, para satisfacer pretensiones y resistencias" 33 .

Por su parte, Manuel Ortells Ramos, fundado en la norma constitucional española, sostiene que la ejecución es parte de la potestad jurisdiccional, debido a que es necesaria para la plenitud de las funciones de esta, siendo de competencia exclusiva de los órganos jurisdiccionales ${ }^{34}$.

En nuestro país gran parte de la doctrina nacional adhiere a esta visión. Y tal vez uno de los argumentos más fuertes para sostener que la ejecución constituye un atributo esencial de la jurisdicción es precisamente el texto constitucional. Allí se contendrían los elementos definitorios de la función jurisdiccional entre los cuales se contempla en forma expresa la facultad de "hacer ejecutar lo juzgado". A partir de lo dispuesto en el artículo 76 de la Constitución, la doctrina tradicional ha construido una noción de jurisdicción ampliamente difundida y que goza de relativa aceptación en nuestro medio. El referido artículo señala lo siguiente:

"La facultad de conocer de las causas civiles y comerciales, de resolverlas y hacer ejecutar lo juzgado corresponde exclusivamente a los tribunales establecidos en la ley. Ni el Presidente de la República ni el Congreso pueden, en caso alguno ejercer funciones judiciales, avocarse causas pendientes, revisar los fundamentos o contenido de sus resoluciones o hacer revivir procesos fenecidos" (lo ampliado es nuestro) ${ }^{35}$.

Sobre la base de esta norma las propuestas doctrinarias tradicionales han entendido que el objetivo de la jurisdicción es "resolver conflictos de intereses suscitados entre particulares"36. Así, se ha definido la jurisdicción como "aquella (facultad) que se ejerce

\footnotetext{
32 Couture (1987) pp. 443 y 444.

33 Montero Aroca (1976) p. 24.

34 Ortells (2005) p. 672.

35 En menor medida, esta conceptualización doctrinaria deriva también del artículo primero del Código Orgánico de Tribunales, que contiene una formulación casi idéntica a la norma constitucional, pues en vez de la expresión "resolverlas", utiliza la voz "juzgarlas".

36 Rodríguez (2009) p. 7. Véase también: Hoyos (2001) p. 6; Colombo (1980) p. 40; Couture (1987) p. 40; Ramos Méndez (2005) p. 206.
} 
cuando hay un juicio, contienda o controversia, suscitado entre dos o más partes que tienen interés en él" 37.

La conceptualización de la actividad jurisdiccional como resolución de conflictos se enmarca dentro de las llamadas teorías subjetivas de la jurisdicción, dentro de las cuales la propuesta de Carnelutti de la justa composición de la litis es de aquellas que gozan de mayor adhesión doctrinaria ${ }^{38}$. Para estas teorías la finalidad de la jurisdicción es la defensa de los derechos subjetivos de los particulares, lo que supone un estado liberal que mantiene el orden entre las personas y que debe conciliar sus intereses en caso de conflicto ${ }^{39}$. En palabras de Damaska, si el Estado es el que debe mantener el equilibrio social corresponde entonces a la justicia la misión de dirimir conflictos o controversias ${ }^{40}$.

No obstante lo anterior, la doctrina tradicional también recoge algunos aspectos de las teorías objetivas, para las cuales la finalidad de la jurisdicción es la actuación del derecho mediante la aplicación de la norma para el caso concreto. Una de las dimensiones desarrolladas por estas teorías -y acogida ampliamente la doctrina nacional y comparada- se centra en la irrevocabilidad de lo fallado, esto es, en el efecto de cosa juzgada ${ }^{41}$. Así, por ejemplo, Colombo define la jurisdicción como "el poder que tienen los tribunales de justicia para resolver, por medio del proceso y con efectos de cosa juzgada, los conflictos de relevancia jurídica en cuya solución les corresponde intervenir" ${ }^{2}$, 43.

De acuerdo a la doctrina tradicional para el ejercicio de esta función se confiere a los tribunales de justicia tres facultades o atribuciones esenciales: (a) conocer, (b) resolver y (c) hacer ejecutar lo juzgado ${ }^{44}$, lo que se conoce también como los momentos de la jurisdicción $^{45}$.

La ejecución corresponde al tercer momento y, a juicio de Colombo, "la generalidad de la doctrina procesal está acorde en considerar la facultad de hacer cumplir lo juzgado como una cuestión inherente a la jurisdicción" ${ }^{46}$. En este mismo sentido, Pereira Anabalón considera que la "vieja discusión doctrinaria en orden a si la ejecución de lo juzgado o imperio integra a no la jurisdicción" hoy se encuentra superada, pues para exigir el cumplimiento de lo resuelto las partes deben necesariamente recurrir a los tribunales de justicia ${ }^{47}$. Por su parte, Casarino señala que aunque en otras legislaciones la tarea de ejecutar ha sido entregada, sea total o parcialmente, al Poder Ejecutivo, en nuestro derecho a la luz de lo

37 Casarino (2007) p. 35.

38 Carnelutti (1944) pp. 155 y 156.

39 Montero (1976) p. 57.

40 Damaska (2000) p. 25.

41 Couture (1987) p. 42; Serra Domínguez (1969) p. 50; Hoyos (2001) p. 6.

42 Соцомво (1980) p. 38.

43 Andrés Bordalí critica la concepción de la jurisdicción como actividad de resolución de conflictos con efecto de cosa juzgada señalando que no es exacta por varias razones. Bordalí (2009) p. 218.

44 Casarino (2007) p. 34.

45 Pereira (1997) p. 7; Colombo (1980) p. 51.

46 Соlombo (1980) p. 61.

47 Pereira (1997) p. 8. 
dispuesto en el artículo 11 del Código Orgánico de Tribunales, no hay dudas que se trata de una facultad privativa del Poder Judicial ${ }^{48}$.

Algo similar se advierte en la jurisprudencia nacional. En efecto, en fallos de la Corte Suprema y de algunas cortes de apelaciones que definen el concepto de jurisdicción no es posible encontrar mención alguna a la facultad de ejecución de los tribunales como un rasgo distintivo y esencial de esta actividad estatal. Por ejemplo, la Corte Suprema recurriendo a la doctrina nacional y al sentido etimológico de la palabra jurisdicción, señala que ella significa "declarar el derecho" ${ }^{49}$. En esta misma línea, algunas cortes de apelaciones definen la jurisdicción como el "poder de juzgar, de declarar el derecho controvertido" 50.

Por su parte, el Tribunal Constitucional en el fallo que declara la inconstitucionalidad del artículo 116 del Código Tributario -a propósito de la labor que realizan los Directores Regionales del Servicio de Impuestos Internos- señala que la jurisdicción consiste en el "poder-deber que tienen los tribunales para conocer y resolver por medio de un proceso y con efecto de cosa juzgada, los conflictos de intereses de relevancia jurídica que se promuevan en el orden temporal dentro del territorio de la República y en cuya solución les corresponda intervenir" ${ }^{21}$. El voto de minoría de este fallo detalla las características -que a juicio de los ministros disidentes- son elementales para determinar si se está o no en presencia de actividad jurisdiccional, a saber: (a) existencia de una controversia entre partes, (b) existencia de un juez que decida tal controversia, (c) pronunciamiento de una sentencia dictada en conformidad a derecho y (d) en materia de formas procesales, el respeto a la bilateralidad de la audiencia ${ }^{52}$.

Sin embargo, y pese a la defensa casi irrestricta de la consideración de la ejecución como elemento esencial de la jurisdicción casi ninguno de los autores nacionales antes mencionados alude siquiera tangencialmente a esta facultad. Y cuando se hace referencia a ella, es curioso constatar que la doctrina solo se concentra en hablar de facultad de imperio, lo que ocurre por ejemplo, cuando se refiere a un elemento que falta en la justicia arbitral. Parece necesario aclarar entonces que si bien el imperio (imperium) y la ejecución y coerción (executio y coercio) están directamente vinculados, son conceptos distintos. De imperio gozan todas las resoluciones judiciales, es decir, tienen fuerza vinculante. El problema surge cuando ellas no son acatadas voluntariamente, recién allí se plantea la posibilidad de la ejecución y eventualmente, el uso de la fuerza pública ${ }^{53}$.

48 Casarino (2007) p. 36.

49 Sentencia de la Corte Suprema, Rol 5864-2006, de 2 de octubre de 2001 y Rol 3493-2010, de 14 de septiembre de 2010.

50 Sentencia de la Corte de Apelaciones de Santiago, Rol 7745-2005, de fecha 30 de enero de 2006; Sentencia de la Corte de Apelaciones de La Serena, Rol 479-2007, de fecha 30 de octubre de 2007.

51 Sentencia del Tribunal Constitucional, Rol 681, considerando 16 ; de 12 de marzo de 2007; Rol 529-2006, de 9 de noviembre de 2006; Rol 533-2006, de 9 de noviembre de 2006 y Rol 478-2006, de fecha 8 de agosto de 2006.

52 Sentencia del Tribunal Constitucional, Rol 604, considerando $4^{\circ}$ del voto disidente, de fecha 20 de marzo de 2007.

53 En este sentido vale la pena recordar la diferencia que existía en el Derecho romano entre el poder de ejecución y la orden del pretor en el período de la República (509 a.c. en adelante). La clara distinción entre la fase in iure -a cargo de un magistrado o pretor- y de la fase in indicio -a cargo de un juez- propia del procedi- 
No obstante lo anterior, la idea de que la ejecución es una facultad esencial de la actividad jurisdiccional se encuentra fuertemente arraigada en la doctrina nacional y ha sido ampliamente difundida. El principal argumento para sostener aquello -como ya se ha mencionado- es el artículo 76 de la Constitución de 1980.

Sin embargo, la historia constitucional muestra otra cosa. A la luz de las actas oficiales de la Comisión de Estudios de la Nueva Constitución las razones del constituyente para incluir esta facultad encuentran su fundamento principalmente en el contexto histórico y político de la época.

Las constituciones anteriores a la de 1980 no contienen alusión alguna a la facultad de imperio dentro del señalamiento de las atribuciones de los tribunales. En la Constitución de 1823, por ejemplo, se advierte solo una mención tangencial cuando se establece que una de las atribuciones de la Corte Suprema es "Proteger, hacer cumplir y reclamar a los otros poderes por las garantías individuales y judiciales" (artículo 146).

Por su parte, la Constitución de 1828 no se refiere a esta facultad, lo mismo que la del 1833. Esta última, bajo el epígrafe "De la administración de justicia” regula la función jurisdiccional en similares términos a los actuales, a saber:

"Art. 108. La facultad de juzgar las causas civiles i criminales pertenece exclusivamente a la Tribunales establecidos por la lei. Ni el Congreso ni el Presidente de la República pueden en ningún caso ejercer funciones judiciales, o avocarse causas pendientes, o hacer revivir procesos fenecidos".

La Constitución de 1925 recoge en forma casi idéntica la formulación de la carta anterior. Las actas oficiales de la Subcomisión de Reformas Constitucionales de aquella época dan cuenta de la nula discusión al momento de redactar esta norma manteniéndose casi el mismo contenido de la carta de 1833, salvo algunas diferencias menores en la redacción ${ }^{54}$. El texto aprobado fue el siguiente:

"Art. 80. La facultad de juzgar las causas civiles y criminales pertenece esclusivamente a los tribunales establecidos por la lei. Ni el Presidente de la República, ni el Congreso, pueden, en caso alguno, ejercer funciones judiciales, avocarse causas pendientes o hacer revivir procesos fenecidos".

miento formulario, se desvanece con la introducción de la cognitio extra ordinem en la época de Augusto. Ello, pues se entregó el conocimiento y resolución de ciertos asuntos a los funcionarios imperiales (magistrados o pretores), quienes sin necesidad de preparar la fórmula ni de la intervención de un juez otorgaban protección jurídica a través de las denominadas "órdenes pretorianas", las que podían ser cumplidas sin necesidad de sentencia del juez. Esta actividad concebida inicialmente para dar solución a asuntos que requerían de una rápida decisión sin dilaciones terminó siendo considerada como ejercicio de la jurisdicción, dando paso con el tiempo al denominado procedimiento extraordinario de la época postclásica. Guzmán Brito (1996) p. 265. Véase también: Topasio (1992) p. 109.

54 Actas oficiales del Proyecto de Nueva Constitución Política de la República del año 1925. Vigésima octava sesión de la Subcomisión de Reformas Constitucionales de 9 de julio de 1925. Ministerio del Interior (Santiago, 1925), p. 365. 
Llama la atención que el constituyente de la época no haya considerado o aludido a la Ley de Organización y Atribuciones de los Tribunales publicada 50 años antes, en 1875. Decimos que llama la atención porque el artículo primero de dicha ley, además de la facultad de juzgar, contemplaba la facultad de conocer y la de ejecutar. No hay actas de las sesiones de las comisiones revisoras del proyecto de esta ley que nos permitan dilucidar el sentido y alcance de esta norma, lo que sí sabemos es que el proyecto original de Francisco Vargas Fontecilla contenía una formulación distinta que no explicitaba las facultades de la jurisdicción, tal como luego quedó plasmado en la Ley de Organización y Atribuciones de los Tribunales ${ }^{55}$.

En 1890 Manuel Egidio Ballesteros publica un libro donde comenta y analiza la citada ley y, a propósito de las facultades de conocer, juzgar y hacer ejecutar lo juzgado señala lo siguiente: "En las dos primeras queda comprendida la jurisdicción y, en la última, el mero imperio" 56 . Incluso señala que la ejecución no es "científicamente hablando" 57 una función propia de los tribunales de justicia, sino que corresponde al Poder Ejecutivo hacer ejecutar lo juzgado, como ocurre en muchos países en que se ha confiado tal función a agentes de la administración. A su juicio, en el caso chileno los jueces al realizar esta tarea lo hacen en función de una "delegación especial de la autoridad ejecutiva, distinta de su poder judicial, que por su naturaleza debiera limitarse a dictar sentencias, declarando derechos" 58 .

Como decíamos -y tal como se desprende de las Actas Oficiales de la Comisión de Estudios de la Nueva Constitución de los años setenta- la decisión de incorporar la expresión hacer ejecutar lo juzgado tuvo una connotación política más que técnico-jurídica. En efecto, conforme a las actas, la historia política del período 1970-1973 operó como fundamento para reforzar el poder de imperio de los tribunales de justicia. Ello se observa nítidamente a la luz de los argumentos que algunos comisionados ofrecen para incorporar la noción de ejecución y agregar dos nuevos incisos al referido articulo 80 de la carta de 1925 .

Tomando como base dicha norma, en la sesión No 252 la Subcomisión de Reforma Constitucional del Poder Judicial propone la inclusión de la facultad de hacer ejecutar lo juzgado en el inciso primero. El comisionado Sr. Alejandro Silva Bascuñán manifiesta que la propuesta constituye una novedad, pese a que ya se encuentra incluida en el Código Orgánico de Tribunales, pero estima que "...la dura experiencia sufrida por el país aconsejaba, que este principio tan esencial que estaba como base general del ordenamiento jurídico nacional, pero no figuraba en la Constitución, debía tener categoría constitucional por la trascendencia que tiene y la experiencia vivida" 59 .

Debido a la necesidad de hacer algunas correcciones en la redacción de este inciso, la Comisión deja su votación para la siguiente sesión y analiza a continuación una segunda

\footnotetext{
55 La propuesta de Vargas Fontecilla era la siguiente: "La jurisdicción o la facultad de administrar justicia, reside esencial i orijinariamente en la Nación, que delega su ejercicio en las autoridades que establece esta Lei”. Ballesteros (1890) p. 12.

56 Ballesteros (1890) p. 11.

57 Ballesteros (1890) p. 12.

58 Ballesteros (1980) p. 12.

59 Acta Oficial de la sesión No 252 celebrada el 21 de octubre de 1976, p. 176.
} 
propuesta de la Subcomisión que consiste en la incorporación de dos nuevos incisos al entonces artículo 80, a saber:

"Para hacer ejecutar sus resoluciones y para practicar o hacer practicar los actos de instrucción que decreten, podrán los Tribunales ordenar directamente a la policía o exigir a otras autoridades el auxilio de la fuerza pública, o disponer de los medios de acción que estimaren conducentes.

La autoridad o el funcionario policial que reciba la orden, no podrá calificar su fundamento ni la justicia o legalidad de la resolución que se trata de ejecutar y deberá cumplir el mandato judicial”.

En efecto, el entonces Presidente de la Corte Suprema y Presidente de la Subcomisión relativa a la Organización y Atribuciones del Poder Judicial, Sr. José María Eyzaguirre propone la idea de incorporar los incisos antes señalados "en vista de lo ocurrido durante los tres años del Gobierno del Presidente Allende ..."60.

El comisionado Sr. Jaime Guzmán concuerda con esta propuesta y en ese sentido señala que considera que si lo que se ha querido es robustecer la facultad de imperio de los tribunales de justicia "aparecería extraño y debilitador de este propósito no elevar a rango constitucional la consecuencia de esta facultad que se les dará de requerir el auxilio de la fuerza pública”. Luego de una breve discusión, la propuesta es acordada en forma unánime por los miembros de la referida comisión ${ }^{61}$.

En la sesión No 253 se vuelve a la revisión del inciso primero y a la discusión sobre la incorporación de la facultad de ejecución. Antes de ello, se debatió la propuesta de los comisionados Sres. Jaime Guzmán y Enrique Evans en orden a agregar -además de la facultad de hacer ejecutar lo juzgado- la de conocer. Ante esta propuesta surgieron algunas discrepancias y el debate giró en torno a si el verbo juzgar se debe tomar en un sentido amplio de modo que comprenda todo el ejercicio de la jurisdicción o si debe entenderse en un sentido restringido, en virtud del cual juzgar sería solo sinónimo de sentenciar.

En este sentido, el comisionado Sr. Jorge Ovalle sostuvo que -conforme al sentido natural y obvio provisto por la definición que ofrece el diccionario- la noción de juzgar supone necesariamente la de conocer, pero señala que no ocurre lo mismo con la de hacer ejecutar lo juzgado ${ }^{62}$. Finalmente y, luego de dos nuevas sesiones, se aprueba el artículo 76, tal como está consagrado en la actualidad en la carta fundamental de 1980.

\footnotetext{
60 Acta oficial de la sesión No 251 celebrada el 19 de octubre de 1976, p. 138.

61 Un antecedente que puede explicar -en parte- el interés y preocupación de los comisionados por regular este punto dice relación con el incumplimiento de resoluciones judiciales por parte de algunas autoridades durante el gobierno de la Unidad Popular. Tanto es así, que en abril de 1973 la Corte Suprema de Justicia adoptó un acuerdo que fue despachado al Presidente de la República como consecuencia de un caso en que -por disposición del Intendente de Santiago de la época- Carabineros de Chile incumple las órdenes dictadas por el Juzgado de Letras de Talagante en un proceso penal. Para mayor información ver: http://www.salvador-allende.cl/ Golpe/antecedentes/ACUERDOSUPREMAALPRESIDENTE.pdf. Página visitada el 24 de octubre de 2012.

62 En esta misma línea, el profesor Andrés Bordalí considera que conocer y resolver se usan como sinónimos, por tanto bastaría utilizar la expresión "resolver". Bordalí (2009) p. 218.
} 
Cabe señalar, por último, que el hecho que las constituciones anteriores a la del ochenta no contemplaran dentro de sus formulaciones la facultad de imperio no es de extrañar. Ello responde al ideario liberal y a la concepción clásica del derecho de la época: el juez no podía ser más que un juez, no podía transformarse en un "opresor" del ciudadano exigiendo el cumplimiento forzado de las obligaciones ${ }^{63}$. Su función era "decir el derecho", razón por la cual se le prohibía todo tipo de facultades de ejecución, pues ello sería tan grave como dar al juez el poder de crear leyes ${ }^{64}$.

\subsection{LA EJECUCIÓN COMO FACULTAD CONEXA DE LA JURISDICCIÓN}

La constatación de que la acción condenatoria "muere" en la sentencia fue lo que llevó a considerar que la ejecución debía ser entregada a la jurisdicción, rompiendo así con la concepción clásica del derecho liberal. A juicio de Marinoni, el estado actual del desarrollo del proceso civil muestra que la sentencia condenatoria es insuficiente para otorgar a las personas la tutela efectiva de sus derechos. Un juez sin poderes para hacer ejecutar lo juzgado hace inviable el acceso a la justicia ${ }^{65}$.

El quiebre con la concepción clásica del derecho se vincula con el desarrollo del Derecho Internacional de los Derechos Humanos y especialmente con la noción de debido proceso y de plazo razonable. En este sentido, la jurisprudencia de la Corte Europea de Derechos Humanos ha sostenido que la ejecución debe ser entendida como parte integral del juicio y que los estados tienen la obligación de organizar estructuras y procedimientos de ejecución justos y eficientes, amén de evitar cualquier retraso excesivo ${ }^{66}$.

Pero no solo se trata de cautelar los derechos del acreedor, sino que el deudor también está protegido por garantías constitucionales. En muchos sistemas europeos rige el principio de la proporcionalidad de la ejecución, en virtud del cual la agresión patrimonial al ejecutado no puede extenderse más allá de lo que es necesario para satisfacer el crédito y para cubrir los gastos de ejecución. De este modo se propende hacia un sistema de ejecución equilibrado de los intereses y derechos de ambas partes del juicio ejecutivo ${ }^{67}$.

Consideraciones de este tipo han llevado al abandono paulatino de las creencias doctrinarias tradicionales que niegan la posibilidad de entregar algunas de las tareas propias de la ejecución a órganos y agentes distintos del juez (ya sea dentro o fuera del circuito judicial) que pudieran dar mayor efectividad y agilidad al recaudo de los créditos.

En este contexto parece necesario entonces reevaluar la tesis que exige una reforma constitucional en caso de propiciar la desjudicialización de la ejecución civil, pues a mi juicio

\footnotetext{
63 Marinoni (2007) p. 141.
}

64 La discusión sobre la necesidad de una reforma constitucional en caso de aprobarse la idea de desjudicializar el procedimiento ejecutivo en nuestro sistema se ha centrado -al menos hasta ahora- exclusivamente en el artículo 76 de la Carta Fundamental, razón por la cual en este artículo se descarta el análisis de otras normas constitucionales que podrían verse afectadas, como el artículo 19 no 24 sobre el derecho de propiedad.

65 Marinoni (2007) p. 142. Sin embargo, la entrega de la facultad de ejecución a los jueces exige el establecimiento de ciertos resguardos, como por ejemplo, que la ejecución surja a petición de parte y que solo se puedan admitir los medios ejecutivos que señala la ley.

66 Sentencia de la Corte Europea de Derechos Humanos, Caso Banca of Vias vs. Moldova, de 6 de noviembre de 2007. También Caso Hornsby vs. Greece, 19 de marzo de 1997; caso Lunari vs. Italia, 11 de enero de 2001.

67 Hess (2010) p. 44. 
y de acuerdo a la experiencia europea ello puede ser perfectamente conciliado con la Carta Fundamental, en atención al carácter conexo de la facultad de hacer ejecutar lo juzgado.

Ya tempranamente un grupo de autores detectó dicho carácter. El propio Carnelutti sostuvo que el procedimiento ejecutivo -cuyo objetivo no es sino procurar la satisfacción del titular del derecho sin o contra la voluntad del obligado- tiene un contenido diverso del proceso jurisdiccional. En su libro "Sistema de Derecho Procesal Civil” utiliza incluso como analogía la relación entre la razón y la fuerza, enfatizando la relación de subordinación de la segunda respecto de la primera ${ }^{68}$.

Por su parte, Serra Domínguez distingue entre jurisdicción en sentido estricto, esto es, los actos esencialmente jurisdiccionales y, jurisdicción en sentido amplio como actos jurisdiccionales por simple conexión, dentro de los cuales se encontraría la ejecución. Este autor postula que la actividad jurisdiccional pura se reduce al juicio, a "decir el derecho", a la cual se unen otras -como la preparación del juicio y la ejecución- solo "por accesión o como actos administrativos" 69 .

Esta visión permitiría sostener que los tribunales no son los únicos órganos llamados a hacer ejecutar lo juzgado, sino que pueden recurrir a otros agentes o autoridades para dar cumplimiento a lo resuelto a través de ciertos mecanismos legales especialmente diseñados para estos efectos.

Guasp y Aragoneses denomina a estos mecanismos "auxilios jurisdiccionales" y los define como "el conjunto de deberes y derechos por los que se exige y presta la actividad necesaria para la consecución de una finalidad procesal reconocida por la ley"70. En esta definición alude a todas aquellas personas públicas o privadas que conforme a la ley tienen un deber de colaboración con la actividad de los jueces, ya sea en el curso del proceso o en la etapa de ejecución de lo resuelto. En el caso de personas públicas, estas pueden formar parte de la organización judicial o bien de otros órganos que prestan servicios a la administración de justicia ${ }^{71}$.

Bien sabemos que nuestro ordenamiento jurídico contempla algunas normas que permiten que la facultad de ejecución pueda ser realizada por autoridades distintas del Poder Judicial. En efecto, el propio artículo 76 de la Constitución y el artículo 11 del Código Orgánico de Tribunales que -en similares términos- se refieren al punto ${ }^{72}$. Los incisos segundo y tercero del artículo 76 señalan lo siguiente:

68 Carnelutti (1944) p. 213.

69 Serra (1969) pp. 49 y 51. Este autor define la jurisdicción como "determinación irrevocable del derecho en un caso concreto seguida en su caso por su actuación práctica”.

70 Guasp y Aragoneses (2005) p. 111.

71 Guasp y Aragoneses (2005) p. 112.

72 "Artículo 11. Para hacer ejecutar sus sentencias y para practicar o hacer practicar las actuaciones que decreten, podrán los tribunales requerir de las demás autoridades el auxilio de la fuerza pública que de ellas dependiere, o los otros medios de acción conducentes de que dispusieren.

La autoridad legalmente requerida debe prestar el auxilio, sin que le corresponda calificar el fundamento con que se le pide ni la justicia o legalidad de la sentencia o decreto que se trata de ejecutar" (lo subrayado es nuestro). Esta norma fue modificada por la Ley 19.665 que introduce modificaciones al Código Orgánico de Tribunales publicada en el Diario Oficial el 9 de marzo de 2000. 
"Para hacer ejecutar sus resoluciones, y practicar o hacer practicar los actos de instrucción que determine la ley, los tribunales ordinarios de justicia y los especiales que integran el Poder Judicial, podrán impartir órdenes directas a la fuerza pública o ejercer los medios de acción conducentes de que dispusieren. Los demás tribunales lo harán en la forma que la ley determine.

La autoridad requerida deberá cumplir sin más trámite el mandato judicial y no podrá calificar su fundamento u oportunidad, ni la justicia o legalidad de la resolución que se trata de ejecutar"73.

Cabe señalar que el origen del artículo 11 de Código Orgánico se remonta a la Ley de Organización y Atribuciones de los Tribunales de 1875 (artículo 10). En las explicaciones a la ley, Matías Ríos González señala a propósito de la facultad de imperio que "para el ejercicio de este poder tienen los tribunales ministros subalternos encargados de cumplir sus órdenes" ${ }^{74}$.

Como se advierte, el objetivo de estas normas es incluir y someter a distinto tipo de autoridades -sean o no miembros del Poder Judicial- en el cumplimiento de las resoluciones judiciales, lo que refuerza la idea que los tribunales pueden valerse de otros órganos o agentes en la ejecución de sus mandatos. Así, la tarea de ejecutar lo fallado se puede entregar a otras personas u organismos, como ocurre en la actualidad en los procedimientos civiles ejecutivos, donde algunas de las labores coactivas o de apremio son realizadas por autoridades administrativas y, en algunos casos, por los auxiliares de la administración de justicia, como ocurre por ejemplo con el receptor judicial o el martillero público ${ }^{75}$. En efecto, ambos funcionarios ejercen labores gravitantes para la ejecución de los créditos, al receptor compete, entre otras, el embargo y retiro bienes del deudor mientras que al martillero la venta de bienes muebles en pública subasta.

\subsection{EXPERIEnCias de desjudicialización en Chile}

Por último, y distinto a lo que pudiera pensarse, años atrás nuestro sistema procesal civil experimentó el fenómeno de la desjudicialización sin que mediara reforma constitucional alguna. En efecto, el año 2003 la Ley 19.903 sobre Procedimiento para Otorgar la Posesión Efectiva de la Herencia traslada el conocimiento y la tramitación de la posesión efectiva desde los tribunales de letras al Servicio de Registro Civil e Identificación ${ }^{76}$.

\footnotetext{
73 Esta norma fue modificada por la Ley $\mathrm{N}^{\circ} 19.519$ publicada en el Diario Oficial el 16 de septiembre de 1997.

74 Ríos (1894) p. 18.

75 En este mismo sentido, Pereira Anabalón si bien comparte la postura tradicional señalada en el capítulo anterior, advierte que la ejecución es una actividad jurisdiccional diversa a la que comprende el conocer y el juzgar. Ello, pues los actos de ejecución están más vinculados -y aquí cita a Couture- "con el hacer que con el decidir" y, además porque requieren del auxilio de otras autoridades para cumplir este cometido. Pereira (1997) p. 8.

76 Ley N 19.903 sobre Procedimiento para Otorgar la Posesión Efectiva de la Herencia, publicada en el Diario Oficial el 10 de octubre de 2003, la que entregó al Servicio de Registro Civil e Identificación.
} 
La ausencia de contencioso y la prescindencia de la intervención del juez fueron los principales argumentos que se utilizaron para optar por la desjudicialización de este procedimiento, todo ello reforzado por la evidencia empírica que revelaba el incremento gradual de estas causas año a año.

Los resultados de un estudio efectuado el año 2000 mostraron que pese a tratarse de una gestión relativamente sencilla, la concesión legal de la calidad de heredero resultaba ser uno de aquellos trámites más engorrosos, complejos y costosos del sistema procesal civil, lo que llevó -entre otras razones- a sus autores a proponer como el "cambio de foro" de estas gestiones $^{77}$.

Ahora bien, es probable que la discusión en torno a la necesidad de reforma constitucional fuese más pacífica o incluso no se diera por tratarse de un asunto voluntario. Estimo que los mismos argumentos que probablemente se tuvieron a la vista en dicha oportunidad (ausencia de controversia) se pueden considerar en el marco de la discusión actual sobre la desjudicialización de la ejecución, toda vez que las gestiones que -conforme al proyecto de ley- se encargarán al oficial de ejecución carecen de un componente jurisdiccional y tienen más bien un carácter administrativo que las asemeja a los actos voluntarios o no contenciosos.

\section{A MODO DE CONCLUSIONES}

Bien sabemos que una cosa es obtener una sentencia favorable y que otra cosa muy distinta es obtener que ella sea cumplida.

En la actualidad nadie duda que las dos dimensiones que comprende la afirmación anterior se entroncan directamente con el derecho del debido proceso y la noción de plazo razonable. En efecto, el derecho de acceso a la justicia contenido en la Convención Americana (artículos 8 y 25) y en la Convención Europea (artículo 6) de Derechos Humanos no se agota en la obtención de una resolución fundada y sobre el fondo del asunto controvertido, sino que impone al sistema judicial la obligación de garantizar que dicha resolución sea cumplida con el auxilio de la fuerza pública si ello es necesario.

Así, la ejecución se yergue como un dispositivo central para la protección de los derechos de las personas, pero de allí no se sigue que solo los jueces sean los llamados a realizar esta labor, como se ha sostenido por parte de la doctrina nacional y comparada.

Varios países europeos han optado por sustraer de la órbita judicial algunas o todas las fases del procedimiento ejecutivo, adoptando diversos modelos que van desde una total descentralización a través de organismos administrativos encargados de la cobranza de los créditos hasta sistemas centralizados donde la ejecución se mantiene en manos de los jueces y/o de funcionarios judiciales.

En el medio de estos dos extremos se observan modelos mixtos con presencia de órganos - públicos y/o privados- con variadas funciones y sujetos a distintos sistemas de control. Con todo, cualquiera sea la modalidad adoptada, la separación entre procedimientos judiciales y procedimientos ejecutivos es hoy uno de los rasgos distintivos de varios de los sistemas de ejecución europeos.

77 Correa y Aguad (2000) pp. 6, 7 y 22. 
En el caso chileno, el principal argumento utilizado para sostener que la ejecución es inescindible de la actividad jurisdiccional y que solo compete a los jueces se basa en el artículo 76 de la carta fundamental. Sin embargo, este argumento se diluye al observar las discusiones del constituyente de la época que dan cuenta de razones políticas para agregar la facultad de ejecución en el inciso primero del referido artículo. Todo indica que no fueron consideraciones de dogmática jurídica ni de carácter jurisprudencial las que inspiraron a los miembros de la Comisión de Estudios de la Nueva Constitución a incluir esta facultad, sino que más bien fueron las repercusiones del gobierno de Allende las que motivaron su incorporación.

A ello hay que añadir que el ordenamiento jurídico chileno establece en el mismo texto constitucional auxilios jurisdiccionales para hacer ejecutar lo juzgado que operan exclusivamente por orden judicial. Los incisos segundo y tercero del artículo 76 y el artículo 11 del Código Orgánico de Tribunales entregan a los jueces la facultad de impartir órdenes a otros agentes u órganos para el cumplimiento de sus decisiones, cuestión que a nadie llama la atención y que viene operando desde 1875 sin mayor discusión.

Por otra parte, la evidencia empírica muestra que el sistema de ejecución de nuestro país no responde con eficiencia al mandato que imponen los tratados internacionales, debido principalmente al diseño procesal y orgánico en que este descansa, lo que se ve potenciado por normativas que incentivan la litigación por parte de los acreedores. En efecto, el $96 \%$ de los casos que conoce la justicia civil son procedimientos ejecutivos, los que en una muy alta proporción terminan con salidas tempranas, sin que el ejecutado llegue siquiera a ser notificado. Y de los casos que siguen adelante, la oposición de excepciones por parte del ejecutado es marginal (2\%).

Si bien este bajo nivel de oposición puede deberse a distintas razones, como el reducido plazo para presentar excepciones o las dificultades para obtener defensa letrada dentro de ese margen de tiempo, más aún si se trata de personas de escasos recursos, lo cierto es que en los hechos la intervención netamente jurisdiccional es menor y se reduce casi exclusivamente a la revisión del título ejecutivo y a la eventual resolución de excepciones, cuando las hay.

Lo anterior muestra que en estricto rigor no hay necesidad de poner en movimiento todo el aparato jurisdiccional y contar con un recurso humano caro y sofisticado como son los jueces para la realización de gestiones que no importan una discusión jurídica y que pueden ser catalogadas como tareas administrativas. Otra cosa distinta es discutir sobre las formas de protección de los derechos del deudor, especialmente aquellos de bajos ingresos, debate que me parece debiera darse tanto si la ejecución es llevada a cabo por un juez como si es entregada a agentes u órganos distintos.

Dado que los requerimientos constitucionales actuales exigen a los estados conciliar, por una parte, el resguardo del derecho a la tutela efectiva del crédito del acreedor y el derecho del deudor a una agresión patrimonial proporcional a lo adeudado y, por otra, el desarrollo de procedimientos ágiles y eficientes, parece indispensable reflexionar detenidamente sobre el sistema de ejecución que queremos.

Las figuras del oficial de ejecución y del juez de ejecución contenidas en el proyecto de ley que crea el Código Procesal Civil responden -a mi juicio- a ambos requerimientos, pues la protección de los derechos de las partes se garantiza con la presencia de un juez 
especializado y la mayor agilidad y eficiencia del sistema con la de un oficial de ejecución, desde luego sujeto al control de la autoridad.

Considero que la necesidad de mejorar nuestro sistema de ejecución es un imperativo imposible de soslayar y no se ven razones para sostener que reformas orientadas a la desjudicialización de la ejecución civil -como la propuesta por el Ejecutivo- exijan como una condición sine qua non la modificación de la Constitución Política para poder ser implementadas.

\section{BIBLIOGRAFÍA}

Andenas, Mads (2205): "National paradigms of civil enforcement: mutual recognition or harmonization in Europe”, en: Adenas, M., Burkhard, H., Oberhammer, P. (editors), Enforcement agency practice in Europe (London, BIICL), pp. 7-23.

Andrews, N. y Turner, R. (2010): "The System of enforcement of civil judgements in England”, en: VAN Rhee, C.H. y Uzelac, A. (editors), Enforcement and enforceabilityTradition and reform, (Oxford, Intersentia), pp. 127-135.

Ballesteros, Manuel Egidio (1890): La lei de organización $i$ atribuciones de los tribunales de Chile. Antecedentes, concordancia i aplicación práctica de sus disposiciones (Santiago).

Bordalí, Andrés (2009): "Organización judicial en el derecho chileno: un poder fragmentado" en Revista Chilena de Derecho, Año 2, No 36: pp. 215-244.

Carnelutti, Francesco (1944): Sistema de Derecho Procesal Civil (Buenos Aires, Editorial Uteha) Tomo I, $598 \mathrm{p}$.

Casarino, Mario (2007): Manual de Derecho Procesal. Derecho Procesal Orgánico (Santiago, Editorial Jurídica de Chile) 192 p.

Cerato, Elisabet (2009): "La ejecución privada por entidad o persona especializada", en: Cachón Cadenas, Manuel y Pico y Junoy, Joan (coord.), La ejecución civil: problemas actuales (Barcelona, Editorial Atelier) pp. 239-250.

Cоцомво, Juan (1980): La jurisdicción, el acto jurídico procesal y la cosa juzgada en el derecho chileno (Santiago, Editorial Jurídica de Chile), 142 p.

Correa, Jorge y Aguad, Alejandra (2000): "Racionalización de la posesión efectiva”, en: Informes de investigación 5, Centro de Investigaciones Jurídicas, Facultad de Derecho, Universidad Diego Portales (Santiago) 19 p.

Couture, Eduardo (1987): Fundamentos de Derecho Procesal Civil (Buenos Aires, Editorial Depalma) $424 \mathrm{p}$.

Damaska, Mirjan (2000): Las caras de la justicia y el poder del Estado. Análisis comparado del proceso legal (Santiago, Editorial Jurídica de Chile) 430 p.

De Hegedus, Margarita y Romero, Alejandro (2010): La ejecución civil, en Tavolari, Raúl (coord.) Derecho Procesal Contemporáneo. Ponencias de las XXII Jornadas Iberoamericanas de Derecho Procesal I (Santiago, Editorial Thomson Reuters) pp. 516-549.

De la Fuente, Nancy (2009): "Desjudicialización y procedimiento de realización de bienes embargados” en Cachón Cadenas, Manuel y Pico y Junoy, Joan (coord.), La ejecución civil: problemas actuales (Barcelona, Editorial Atelier) pp. 465-475. 
Del Valle Valenzuela, Alfredo (1909): La Lei de organización y atribuciones de los tribunales $i$ sus modificaciones (Santiago, Imprenta Cervantes).

Guasp, Jaime y Aragoneses, Pedro (2005): Derecho Procesal Civil. Introducción y Parte General (Madrid, Editorial Thomson Civitas) $332 \mathrm{p}$.

Guzmán Brito, Alejandro (1996): Derecho Privado Romano (Santiago, Editorial Jurídica de Chile) 802 p.

Hess, Burkhard (2005): "Comparative analysis of the national reports", en: Adenas, M., Hess, B., Oberhammer, P., (editors) Enforcement agency practice in Europe (London, BIICL) pp. 25-51.

Hess, Burkhard (2010): "Different enforcement structures", en: VAN RHEe, C.H. y UzELAC, A. (editors), Enforcemnet and enforceability-Tradition and reform, (Oxford, Intersentia), pp. 41-56.

Hoyos, Francisco (2001): Temas fundamentales de Derecho Procesal (Santiago, Editorial Jurídica de Chile), $281 \mathrm{p}$.

Marinoni, Luis Guillerme (2007): Derecho fundamental a la tutela jurisdiccional efectiva. Del proceso civil clásico a la noción de tutela jurisdiccional efectiva (Lima, Editorial Palestra) $342 \mathrm{p}$.

Marinoni, Luis Guillermo, Pérez Ragone, Álvaro y Núñez, Raúl (2010): Fundamentos del Proceso Civil. Hacia una teoría de la adjudicación (Santiago, Editorial Abeledo Perrot LegalPublishing), 510 p.

Montero Aroca, Juan (1976): Introducción al Derecho Procesal. Jurisdicción, acción y proceso (Madrid, Editorial Tecnos) 305 p.

Ortells Ramos, Manuel (2005): Derecho Procesal Civil (Navarra, Editorial Thomson Aranzadi) $1104 \mathrm{p}$.

Ortells Ramos, Manuel (2010): "Informe nacional España en Tavolari, en: Raúl (coord.) Derecho Procesal Contemporáneo. Ponencias de las XXII Jornadas Iberoamericanas de Derecho Procesal (Santiago, Editorial Thomson Reuters) pp. 549-618.

Pereira Anabalón, Hugo (1997): La cosa juzgada en el proceso civil (Santiago, Editorial Jurídica ConoSur), 262 p.

Pérez Ragone, Álvaro y Miquel Sala Raquel (2010): Ejecución transfronteriza en la Unión Europea: Reflexiones desde Budapest (Valparaíso, documento inédito).

Pérez Ragone, Álvaro (2009): Principios de la ejecución civil singular (Valparaíso, documento inédito).

Ramos Méndez, Francisco (2005): El sistema procesal español (Barcelona, Editorial Atelier) $406 \mathrm{p}$.

Ried, José Miguel (2006): “Juicio ejecutivo y protección del crédito: su impacto en el mundo económico y comercial”, en: Silva, José Pedro; García, José Francisco y LetuRIA, Francisco J. (editores) Justicia civil y comercial: una reforma pendiente. Bases para el diseño de la reforma procesal civil (Santiago, Fundación Libertad y Desarrollo, Pontificia Universidad Católica de Chile y Universidad Autónoma de Madrid) pp. 475-491.

Ríos, Matías (1894): Esplicaciones de la Lei de Organización i Atribuciones de los Tribunales, (Santiago, Editorial Imprenta Ercilla) 274 p. 
Rodríguez Papic, Ignacio (2009): Procedimiento Civil. Juicio ordinario de mayor cuantía (Santiago, Editorial Jurídica de Chile) 316 p.

Serra Domínguez, Manuel (1969): Estudios de Derecho Procesal (Barcelona, Editorial Ariel), 805 p.

Théry, Phillippe (1997): "Le droit français de l'execition”, en De Leval, George (editor), Seizure and overindebtedness in the European Union, (The Netherlands, Kluwer Law International) pp. 261-318.

Topasio, Aldo (1992): Procedimiento Civil Romano (Valparaíso, Editorial Edeval) 123 p.

Turner, R. (2010): “A model of an enforcement regime”, en Van Rhee, C.H. y Uzelac, A. (editors), Enforcement and enforceability-Tradition and reform, (Oxford, Intersentia) pp. 137-146.

Villadiego, Carolina (2008): Estudio Comparativo Cobranzas de deudas y procedimientos de ejecución en Europa, Centro de Estudios de Justicia de las Américas (CEJA), Santiago, 41 p. Disponible en: http:/www.cejamericas.org/portal/index.php/en/biblioteca/biblioteca-virtual/cat_view/43-documentos/66-informes-comparativos?start=15.

\section{JURISPRUDENCIA}

Sentencia de la Corte Europea de Derechos Humanos, Caso Banca of Vias vs. Moldova, de 6 de noviembre de 2007.

Sentencia de la Corte Europea de Derechos Humanos, Caso Hornsby vs. Greece, de 19 de marzo de 1997.

Sentencia de la Corte Europea de Derechos Humanos, caso Lunari vs. Italia, de 11 de enero de 2001,

Sentencia de la Corte Suprema, Rol 5864-2006, de 2 de octubre de 2001.

Sentencia de la Corte Suprema, Rol 3493-2010, de 14 de septiembre de 2010.

Sentencia de la Corte de Apelaciones de Santiago, Rol 7745-2005, de fecha 30 de enero de 2006.

Sentencia de la Corte de Apelaciones de La Serena, Rol 479-2007, de fecha 30 de octubre de 2007.

Sentencia del Tribunal Constitucional, Rol 681-2007, de 26 de marzo de 2007.

Sentencia del Tribunal Constitucional, Rol 529-2006, de 9 de noviembre de 2006.

Sentencia del Tribunal Constitucional, Rol 533-2006, de 9 de noviembre de 2006.

Sentencia del Tribunal Constitucional, Rol 478-2006, de fecha 8 de agosto de 2006.

\section{TeXtos Legales}

Ley Orgánica 1/2009, de 3 de noviembre, complementaria de la Ley de reforma de la legislación procesal para la implantación de la nueva Oficina Judicial, por la que se modifica la Ley Orgánica 6/1985, de 1 de julio, del Poder Judicial.

Ley 19.665 que introduce modificaciones al Código Orgánico de Tribunales publicada en el Diario Oficial el 9 de marzo de 2000. 
Ley 19.903 sobre Procedimiento para Otorgar la Posesión Efectiva de la Herencia, publicada en el Diario Oficial el 10 de octubre de 2003, la que entregó al Servicio de Registro Civil e Identificación.

Mensaje S.E. La Presidenta de la República con el que se inicia un proyecto de ley que aprueba el Nuevo Código Procesal Civil. Santiago, 8 de mayo de 2009. Mensaje No 398-357/.

Circular No 24 de 24 de abril del 2008 sobre "Tratamiento tributario del castigo de créditos incobrables".

Libro Verde sobre la eficacia en la ejecución de las resoluciones judiciales en la unión europea: embargo de activos bancarios (24 de octubre de 2006).

Libro Verde sobre la eficacia de la ejecución de las resoluciones judiciales en la Unión Europea: transparencia de los activos patrimoniales de los deudores (6 de marzo de 2008).

Reglamento (CE) No 805/2004 del Parlamento Europeo y del Consejo de 21 de abril de 2004 que se establece un título ejecutivo europeo para créditos no impugnados.

Reglamento (CE) No 1896/2006 del Parlamento Europeo y del Consejo, de 12 de diciembre de 2006, por el que se establece un proceso monitorio europeo.

Reglamento 861/2007 del Parlamento Europeo y del Consejo de 11 de julio de 2007 por el que se establece un proceso europeo de escasa cuantía.

\section{INFORMES}

Centro de Estudios de Justicia de las Américas (2011): Informe Final "Estudio de Análisis de Trayectoria de las Causas Civiles en los Tribunales Civiles de Santiago" (Santiago).

Centro de Estudios de Justicia de las Américas (2011): Juzgado de Cobranza Laboral y Previsional de Santiago: Informe de gestión elaborado para el CEJA (Santiago).

Pontificia Universidad Católica de Chile (2006): Informe sobre desjudicialización de competencias en materia civil, elaborado por el profesor de derecho procesal civil, Jorge Vial Álamos (Santiago).

\section{PÁGINAS WEB}

Union Internationale des Huissiers de Justice. Informations, Europe [en línea] [Consulta: 24 de octubre, 2012] <http://www.uihj.com>

Les huisssiers de Justice À votre SERvice. [en línea] [Consulta: 24 de octubre de 2012] <http://www.huissier-justice.fr/>.

Servicios de Impuestos Internos. Documentos. Circulares [en línea] Santiago, Chile, SII. [Consulta: 24 de octubre de 2012] <http://www.sii.cl/documentos/circulares/2008/ circu24.htm>.

Salvador Allende, Antecedentes del Golpe de Estado. Acuerdo de la Corte Suprema (12 de abril de 1973) [en línea] Santiago, Chile. [Consulta: 24 de octubre de 2012] <http:// www.salvador-allende.cl/Golpe/antecedentes/ACUERDOSUPREMAALPRESIDENTE.pdf>. 